\title{
The aged and the ill: A decade of surgical aortic valve replacement outcomes
}

\author{
Lillian L. Tsai, AB, Hanna A. Jensen, MD, PhD, and Vinod H. Thourani, MD
}

See related article on pages 571-8.

In this issue of The Journal of Thoracic and Cardiovascular Surgery, Agarwal and colleagues ${ }^{1}$ characterize in-hospital mortalities and rates of adverse neurologic events after surgical aortic valve replacement (SAVR) in a large cohort of 104,699 admissions stratified by factors including age, surgical risk, hospital volume, and procedure type. In an analysis of the 2002 through 2011 Nationwide US Inpatient Sample (NIS) database, they report that patients with advanced age and high surgical risk have increased in-hospital mortality and incidence of adverse neurologic events.

Even today, as many as a third of patients with severe symptomatic aortic stenosis or regurgitation do not receive surgery because of the perceived risk associated with advanced age or comorbidities. ${ }^{2,3}$ A realistic account of outcomes in this cohort is thus extremely important. The benchmark for transcatheter therapies also requires comparable data of modern criterion standard surgical outcomes; reports of this kind are invaluable in setting the bar for novel interventions. The study by Agarwal and colleagues ${ }^{1}$ complements another current report on 141,905 patients from the Society of Thoracic Surgeons (STS) national surgical database, ${ }^{4}$ one of the largest contemporary studies to characterize rates of mortality and morbidity in a real world cohort of patients undergoing SAVR.

The volume of data presented in this report is staggering; however, we can observe the following overall findings: inhospital mortality was $2.5 \%$ for patients undergoing isolated SAVR and $3.7 \%$ for patients undergoing SAVR with concomitant coronary artery bypass grafting. The neurologic event rates were $2.0 \%$ for patients with isolated

\footnotetext{
From the Division of Cardiothoracic Surgery, Joseph B. Whitehead Department of Surgery, Structural Heart and Valve Center, Emory University School of Medicine, Atlanta, Ga.

Disclosures: V.H.T. serves on advisory boards for St Jude Medical, Edwards Lifesciences, Boston Scientific, and Abbott Medical. V.H.T. performs research for Medtronic, Edwards Lifesciences, St Jude Medical, Directflow, and Sorin Medical. All other authors have nothing additional to disclose with regard to commercial support.

Received for publication June 8, 2015; accepted for publication June 10, 2015; available ahead of print July 3, 2015

Address for reprints: Vinod H. Thourani, MD, Emory University Hospital Midtown, 550 Peachtree St, NE, 6th Floor, Medical Office Tower, Atlanta, GA 30308 (E-mail: vthoura@emory.edu)

J Thorac Cardiovasc Surg 2015; 150:579-80

$0022-5223 / \$ 36.00$

Copyright (C) 2015 by The American Association for Thoracic Surgery

http://dx.doi.org/10.1016/j.jtcvs.2015.06.016
}

SAVR and $2.9 \%$ for patients with SAVR plus coronary artery bypass grafting, respectively. In a multivariable logistic regression analysis, increasing age, increasing comorbidities, and female sex were associated with increased in-hospital mortality, whereas a high-volume hospital setting (defined as $>200$ SAVRs per year)

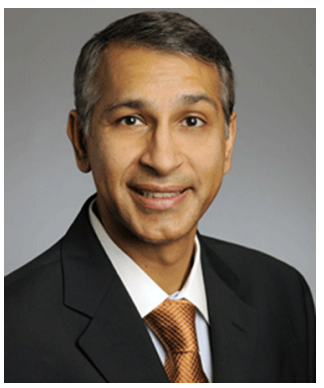
was protective. No analysis of operative era was provided, signifying that the combined results reflect a decade of operative techniques.

Instead of using a standardized score such as the STS predicted risk of mortality (PROM) for adjustment, Agarwal and colleagues ${ }^{1}$ developed their own multivariable regression model that incorporates age, sex, total number of Elixhauser comorbidities, ${ }^{5}$ and hospital characteristics. Undoubtedly the choice of risk stratification was limited by the data available in the source database. This method of characterizing operative risk makes it challenging to reproduce or apply the findings directly to other studies and real-world hospitals, which mostly use the standardized STS predicted risk of mortality or euroSCORE risk estimates.

Indeed, the greatest limitations of this study stem from the limitations of the source database. The NIS database is the largest publicly available all-payer database in the United States and includes data from 8 million discharges annually at more than 1000 hospitals. It is an administrative database rather than a medical registry. Because information is recorded by admission rather than by patient, factors such as reoperation, cardiopulmonary bypass time, and crossclamp time are unavailable. These are aspects that have a considerable effect on mortality and neurologic event risk after SAVR. ${ }^{6,7}$ This may be especially important for elderly patients, for whom cardiac reoperation has been shown to carry a markedly higher risk of mortality and morbidity. ${ }^{8-10}$ Furthermore, the NIS database relies on International Classification of Diseases, Ninth Revision and Healthcare Cost and Utilization Projection Clinical Classification Software codes to indicate outcomes. Events are not adjudicated, and no quality control measures for medical accuracy are implemented nationally or site-by-site by hospital audits. It is not clear, for example, whether all strokes were confirmed by imaging, as they are in the STS national database. Finally, data are available from the hospital admission only, and no follow-up is provided. 
Some interesting parameters that are not found in other national cardiothoracic surgical registries, such as hospital teaching status, urban setting, and volume load, are, however, included in the NIS database. It would have been interesting to see a report focused more on these aspects, which largely remain unclarified in larger cohorts of SAVR. An interested reader can find some information summarized in the online supplement. We hope there is a future article planned to elucidate the impact of hospital setting on SAVR outcomes, free of the burden of extensive subgroup analysis according to patient-specific factors.

The sheer magnitude of data may make it challenging to identify a cohesive message in this study, especially because the overall results are expected and unsurprising. It is well established and decidedly intuitive that advanced age and high surgical risk are associated with poor survival, increased operative risk, and higher rates of neurologic complications. ${ }^{2,6,7}$ Ultimately, the findings described in this study validate the rates of mortality and adverse neurologic events in patients undergoing aortic valve surgery. It remains in the hands of surgeons to find innovative methods to decrease stroke rates after SAVR. In this spirit, the National Institutes of Health Cardiothoracic Surgery Network has embarked on a randomized trial of techniques that potentially will decrease this catastrophic complication during SAVR.

\section{References}

1. Agarwal S, Garg A, Parashar A, Svensson LG, Tuzcu EM, Navia J, et al. In-hospital mortality and stroke following surgical aortic valve replacement: a nationwide perspective. J Thorac Cardiovasc Surg. 2015;150:571-8.e8.

2. Iung B, Cachier A, Baron G, Messika-Zeitoun D, Delahaye F, Tornos P, et al. Decision-making in elderly patients with severe aortic stenosis: why are so many denied surgery? Eur Heart J. 2005;26:2714-20.

3. George I, Yerebakan H, Kalesan B, Nazif T, Kodali S, Smith CR, et al. Age alone should not preclude surgery: contemporary outcomes after aortic valve replacement in nonagenarians. J Thorac Cardiovasc Surg. 2014;148:1360-9.e1.

4. Thourani VH, Suri RM, Gunter RL, Sheng S, O'Brien SM, Ailawadi G, et al. Contemporary real-world outcomes of surgical aortic valve replacement in 141,905 low-risk, intermediate-risk, and high-risk patients. Ann Thorac Surg. 2015;99:55-61.

5. Elixhauser A, Steiner C, Harris DR, Coffey RM. Comorbidity measures for use with administrative data. Med Care. 1998;36:8-27.

6. Biancari F, Onorati F, Mariscalco G, De Feo M, Messina A, Santarpino G, et al. Frequency of and determinants of stroke after surgical aortic valve replacement in patients with previous cardiac surgery (from the Multicenter RECORD Initiative). Am J Cardiol. 2013;112:1641-5.

7. Messé SR, Acker MA, Kasner SE, Fanning M, Giovannetti T, Ratcliffe SJ, et al; Determining Neurologic Outcomes from Valve Operations (DeNOVO) Investigators. Stroke after aortic valve surgery: results from a prospective cohort. Circulation. 2014;129:2253-61.

8. Kirsch M, Nakashima K, Kubota S, Houël R, Hillion ML, Loisance D. The risk of reoperative heart valve procedures in octogenarian patients. J Heart Valve Dis. 2004;13:991-6; discussion 996.

9. Scherner M, Madershahian N, Kuhr K, Rosenkranz S, Stöger E, Rahmanian P, et al. Aortic valve replacement after previous heart surgery in high-risk patients: transapical aortic valve implantation versus conventional aortic valve replacement-a risk-adjusted and propensity score-based analysis. J Thorac Cardiovasc Surg. 2014;148:90-7.

10. Park CB, Suri RM, Burkhart HM, Greason KL, Dearani JA, Schaff HV, et al. Identifying patients at particular risk of injury during repeat sternotomy: analysis of 2555 cardiac reoperations. J Thorac Cardiovasc Surg. 2010;140: 1028-35. 